\title{
Leopard Panthera pardus density in southern Mozambique: evidence from spatially explicit capture-recapture in Xonghile Game Reserve
}

\author{
Paolo Strampelit, Leah Andresen, Kristoffer T. Everatt \\ Michael J. Somers and J. Marcus Rowcliffe
}

\begin{abstract}
Rigorous status estimates of populations of large carnivores are necessary to inform their management and help evaluate the effectiveness of conservation interventions. The African leopard Panthera pardus faces rising anthropogenic pressures across most of its contracting sub-Saharan range, but the scarcity of reliable population estimates means that management decisions often have to rely on expert opinion rather than being based on sound evidence. This is particularly true for Mozambique, where little is known about the ecology or conservation status of leopard populations as a result of prolonged armed conflict. We used camera trapping and spatially explicit capturerecapture models to provide a leopard density estimate in Xonghile Game Reserve in southern Mozambique, which is part of the Greater Limpopo Transfrontier conservation initiative. The estimated population density was $2.60 \pm \mathrm{SE} 0.96$ leopards $/ 100 \mathrm{~km}^{2}$. Our study provides a baseline leopard density for the region and the first empirical density estimate for southern Mozambique. Our results also suggest that current methods used to set trophy hunting quotas for leopards, both in Mozambique and elsewhere in Africa, may be leading to unsustainable quotas, which highlights the importance of robust empirical data in guiding conservation policy.
\end{abstract}

Keywords Camera trap, density estimation, leopard, Mozambique, Panthera pardus, SECR, spatially explicit capture-recapture, trophy hunting

\section{Introduction}

The leopard Panthera pardus is categorized as Vulnerable on the IUCN Red List. Its risk of extinction is particularly high in fragmented landscapes because of low

Paolo Strampelli (Corresponding author) Department of Zoology, Wildlife Conservation Research Unit, Abingdon Road, University of Oxford, Oxford, OX13 5QL, UK. E-mail paolo.strampelli@gmail.com

Leah Andresen, Kristoffer T. Everatt and Michael J. Somers Centre for Wildlife Management, Mammal Research Institute \& Centre for Invasion Biology, University of Pretoria, Pretoria, South Africa

J. Marcus Rowcliffe Institute of Zoology, Zoological Society of London, London, UK

Received 24 June 2017. Revision requested 13 September 2017.

Accepted 15 January 2018. First published online 7 September 2018. densities, large spatial requirements and potential for conflict with humans (Nowell \& Jackson, 1996; Balme et al., 2010). Leopard populations in Africa are increasingly threatened by increasing anthropogenic pressures, leading to concern for the conservation of the species and calls for reliable population estimates to inform conservation management (Jacobson et al., 2016). In the absence of robust population estimates, management decisions often rely on expert opinion rather than being based on sound evidence, making it difficult to identify areas of concern, prioritize conservation investments, or evaluate the effectiveness of interventions (Gray \& Prum, 2012; Balme et al., 2014).

Density estimation, such as with capture-recapture modelling, has become a key process in wildlife ecology, conservation and management (Gray \& Prum, 2012). Initially, capture-recapture techniques estimated abundance rather than density, and relied on estimating the survey's effective sampled area to obtain the latter. However, no theoretical basis exists for this process, and the reliability of this approach is therefore questionable (Efford, 2004; Borchers \& Efford, 2008; Royle et al., 2009). Recently developed methodologies, known as spatially explicit capture-recapture, overcome these issues by estimating density directly as an explicit parameter (Efford, 2004; Royle et al., 2009).

Since their first application to tiger populations in India (Karanth, 1995), capture-recapture techniques have been employed to obtain density estimates of most large carnivores, including leopards in several African countries, such as South Africa (Balme et al., 2009; Chase Grey et al., 2013; Swanepoel et al., 2015), Gabon (Henschel et al., 2011) and Namibia (Stein et al., 2011). Nevertheless, there is still a paucity of such data across much of the continent, precluding effective conservation management (Balme et al., 2014). In Mozambique armed conflicts during much of the latter half of the 2oth century have contributed to significant declines in wildlife populations (Hatton et al., 2001) and have hindered conservation, and there has been little research conducted on the status, distribution or ecology of the leopard.

Leopards can be legally hunted for trophies in several locations in Mozambique, with the current annual quota set at 120 permits (CITES, 2007). This quota is based on an estimation of the overall abundance of leopards in Mozambique by Martin \& de Meulenaer (1988), who employed a predictive model, estimating a population of 37,542 leopards in the 
country based on a mean density of $0.10 / \mathrm{km}^{2}$ (10 leopards/ $100 \mathrm{~km}^{2}$ ). This estimate has been widely criticized because the model omitted important factors such as anthropogenic mortality and prey availability and assumed that leopards occur at maximum potential densities in all available habitats (Jackson, 1989; Balme et al., 2010). Nevertheless, it formed the basis of the most recent increase in the trophy hunting quota, mainly because alternative estimates of population densities are not available (CITES, 2007). A more accurate assessment of leopard populations in Mozambique is needed to determine the reliability of the methods currently employed to set the hunting quota, and to ensure that future changes are based on robust data.

Here we use closed-population spatially explicit capturerecapture methodology to estimate the density of leopards in Xonghile Game Reserve in southern Mozambique. The aim of the study was to obtain the first empirical density estimate for a leopard population in southern Mozambique and present information to guide management and provide a baseline for the assessment of conservation interventions, and to explore the implications of our findings for trophy hunting.

\section{Study area}

Xonghile Game Reserve (Fig. 1) is a $450 \mathrm{~km}^{2}$, unfenced, legally protected area in southern Mozambique. Its northern border is c. $13 \mathrm{~km}$ south of Limpopo National Park, the country's largest national park. It borders South Africa's Kruger National Park to the west and unprotected land to the north, east and south, and is part of the Greater Limpopo Transfrontier Conservation Area, a transboundary initiative linking protected parks and reserves in Mozambique, South Africa and Zimbabwe via nonprotected areas. The predominant habitat in the Reserve consists of sand plains (sandveld) characterized by low woodlands and thickets on deep sandy soils, and short-grass pans (seasonally flooded depressions). Although populations of large mammals in the region were severely depleted during the 1964-1992 armed conflicts (Hanks, 2000), the progressive removal of fencing along the border of Kruger National Park since 2005 has provided opportunities for wildlife to move into the area. No human population permanently resides in the Reserve, with the main anthropogenic impacts coming from relatively low levels of poaching for bushmeat, anti-poaching efforts, and low levels of tourism (LA \& KTE, unpubl. data). Trophy hunting does not currently take place in the Reserve.

\section{Methods}

\section{Camera trapping}

Twenty-nine digital motion-activated cameras of various models (HC50o, Reconyx, Holmen, USA; Tiny W-2, Spy
Point, Victoriaville, Canada; Trophy Cam, Bushnell, Overland Park, USA) were deployed at 26 stations over c. $300 \mathrm{~km}^{2}$ in the Xonghile Game Reserve (Fig. 1) during 24 August-23 November 2012. Twenty-three stations were equipped with a single camera and three stations with two cameras each.

The majority of stations (23) were located $0.5-3 \mathrm{~km}$ apart, ensuring that multiple cameras were likely to be present in an individual leopard's home range. Three stations were placed 5-6 km from the nearest station. There was therefore a possibility that an individual's home range did not contain a station, but this is unlikely given the low prey densities in the study area (LA \& KTE, unpubl. data), and spatially explicit capture-recapture models allow for the presence of such gaps in the trap array when estimating density (Borchers \& Efford, 2008). Cameras were set on trees along roads and game trails at a height of $35 \mathrm{~cm}$. The survey duration was 92 days, which was considered adequate for assuming demographic closure and is consistent with previous studies of large felids (Karanth, 1995; Alexander et al., 2015; Boron et al., 2016).

\section{Density estimation}

Density was modelled in a spatially explicit capture-recapture framework, using the package secr (Efford, 2015) in $R$ v. 3.2.3 (R Development Core Team, 2015). A maximum-likelihood framework was chosen over a Bayesian one to make results comparable with other studies (Noss et al., 2013; Tobler \& Powell, 2013) and because computation times are shorter (Efford, 2015).

Leopards were identified from their pelage patterns and sexed by visual inspection of external genitalia. We chose the flank with the greater number of captures (left) for identification of individual leopards. Individual spatial capture and trap effort histories were developed following recommended procedures (Efford, 2015), with each day (24 hours) treated as a separate sampling occasion (Goldberg et al., 2015). Information on varying effort from different camera stations (the number of days each camera was active) was included to improve estimates of detection probability. We increased the buffer width around the trapping grid until density estimates stabilized, ensuring that no individual outside the buffer area could be captured, and fitted a half-normal detection function to the distance between the centre of the home range and the camera station. This is the most commonly used function in spatial capture-recapture analyses (Efford, 2004; Boron et al., 2016) and describes the probability of capture (P) of an individual $i$ at a trap $j$ as a function of distance $d$ from the activity centre of the individual to the trap, as follows: $\mathrm{P} i j=g o \exp \left(-d i j^{2} /\left(2 \sigma^{2}\right)\right.$, where $g o$ is the probability of capture at the exact centre of the home range, and $\sigma$ is a spatial parameter related to home range size 


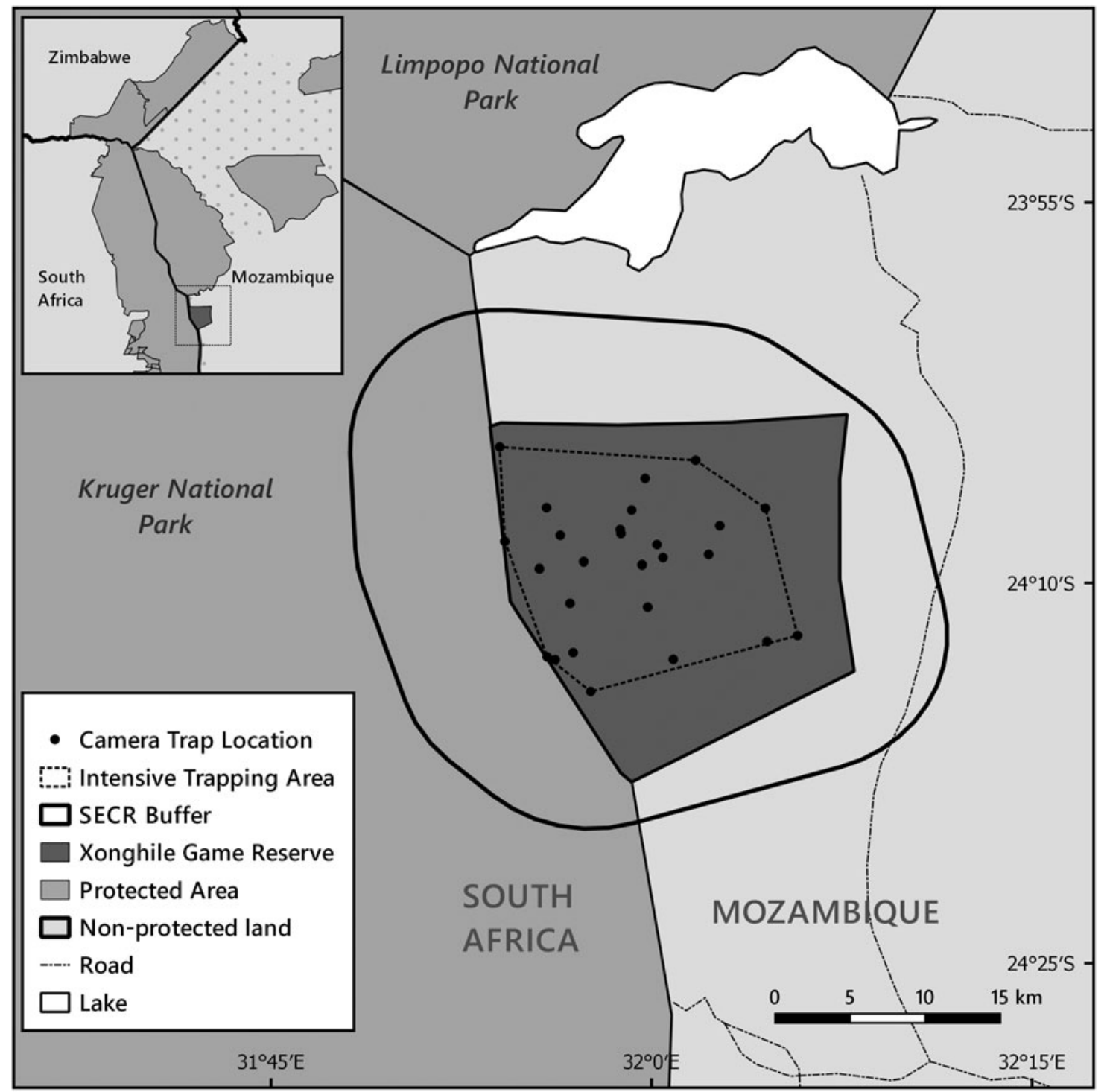

FIG. 1 Xonghile Game Reserve, with camera locations and intensive trapping area within a $10 \mathrm{~km}$ buffer zone, as required by the spatially explicit capture-recapture models. Inset map: the Reserve in the context of the wider Greater Limpopo Transfrontier conservation initiative, comprising protected (grey) and non-protected areas (dotted).

(Efford, 2004). We fitted a Bernoulli or binomial encounter model to the data because this is most relevant to camera trapping studies; under this model an individual can be recorded at different camera stations during one sampling occasion, but only once at each station (Royle et al., 2009; Noss et al., 2013).

Given that male and female leopards have different ranging patterns (Bailey, 1993; Kittle et al., 2017), with a potential impact on capture parameters, sex was modelled as a covariate (Sollmann et al., 2011; Tobler \& Powell, 2013; Goldberg et al., 2015). This was achieved by fitting a hybrid mixture model, which accommodates individuals of unknown sex (Efford, 2015). The impact of sex on both parameters go and $\sigma$ was tested through the comparison of four alternative models using the Akaike Information Criterion, adjusted for small sample size (AICc; Burnham \& Anderson, 2002): secr.o (null model), secr.sex.go ( $g$ o varies between males and females), secr.sex. $\sigma$ ( $\sigma$ varies between males and females), and secr.sex (both go and $\sigma$ vary between males and females; Efford, 2015; Boron et al., 2016).

\section{Results}

\section{Sampling effort and capture success}

A total sampling effort of 1,021 trap nights by 26 stations (mean trap nights per camera $=39.3$ ) yielded 57 leopard capture events. Of these, 31 (54\%) were used to identify nine individual leopards (five males, two females, two unsexed); the remaining 26 events ( $46 \%$ ) were not suitable for identification (because of poor image quality and/or the wrong flank being captured) and were therefore discarded. Capture 
TABLE 1 Model selection parameters for spatially explicit capture-recapture models in $R$ package secr.

\begin{tabular}{|c|c|c|c|c|c|c|}
\hline Model & Description & $\mathrm{AICc}^{1}$ & $\Delta \mathrm{AICc}^{2}$ & $\begin{array}{l}\text { AIC model } \\
\text { weights }\end{array}$ & $K^{3}$ & $\begin{array}{l}\text { Model } \\
\text { deviances }\end{array}$ \\
\hline secr.0 & No variation between sexes & 360.364 & 0.000 & 1 & 4 & 324.364 \\
\hline secr.sex. $\sigma$ & $\sigma^{4}$ varies between sexes & 370.835 & 10.471 & 0 & 5 & 322.663 \\
\hline secr.sex.g0 & $g 0^{5}$ varies between sexes & 371.280 & 10.916 & 0 & 5 & 323.281 \\
\hline secr.sex & $g 0$ and $\sigma$ vary between sexes & 394.663 & 34.299 & 0 & 6 & 322.835 \\
\hline
\end{tabular}

${ }^{1}$ Akaike Information Criterion, adjusted for small sample size.

${ }^{2}$ Difference from best ranking (lowest AIC) model.

${ }^{3}$ Number of model parameters.

${ }^{4}$ Spatial parameter related to home range size.

${ }^{5}$ Probability of capture at the home range centre.

frequencies were 9, 3, 2, 2 and 1 for the five males; 6 and 4 for the two females; and 3 and 1 for the two unsexed individuals.

\section{Density estimation}

The best model (AICc $=360.36)$ did not allow go or $\sigma$ to vary with sex (secr.o), and received significantly more support than the next best alternative (secr.sex. $\sigma, \Delta$ AICc $=10.47$; Table 1 ).

The leopard density estimate of the best-fitted model (secr.o) was $2.60 \pm \mathrm{SE} 0.96$ adults $/ 100 \mathrm{~km}^{2}$. Capture probability at the centre of the home range ( $g o$ ) was estimated to be $0.043 \pm \mathrm{SE} 0.013$, and the spatial parameter $(\sigma)$ to be $1,936 \pm$ SE $279 \mathrm{~m}$ (Table 2). Buffer width stabilized at $10,000 \mathrm{~m}$, as reported by similar leopard density studies (Gray \& Prum, 2012; Borah et al., 2013).

\section{Discussion}

\section{Leopard density}

Our study provides a baseline leopard density estimate for a relatively well-protected area and the first empirical estimate for a leopard population in Mozambique. Using spatially explicit capture-recapture models we estimated leopard density in the Xonghile Game Reserve to be $2.60 \pm \mathrm{SE} 0.96$ adults $/ 100 \mathrm{~km}^{2}$. Although this is low compared to studies elsewhere in sub-Saharan Africa, it is higher than estimates from other protected areas in southern Africa: 0.60 leopards $/ 100 \mathrm{~km}^{2}$ in the dry savannahs of the Kalahari Gemsbok National Park (South Africa; Bothma \& Le Riche, 1984), $0.62 / 100 \mathrm{~km}^{2}$ in the savannah/woodland Cederberg Wilderness Area (South Africa; Martins \& Harris, 2013) and 1.50/100 $\mathrm{km}^{2}$ in the savannah habitat of the Kaudom Game Reserve, Namibia (Stander et al., 1997).

In South Africa's Kruger National Park, contiguous with the Reserve's western border, high leopard densities of $30.3 / 100 \mathrm{~km}^{2}$ were reported for the Sabie riverine area (Bailey, 1993), and $12.7 / 100 \mathrm{~km}^{2}$ in the N'wantesi concession (Maputla et al., 2013). We believe the observed differences are probably a reflection of different habitats, and consequently prey availability, between sites. Whereas density estimates from Kruger
TABLE 2 Parameters and density estimated by the best model (secr.o).

\begin{tabular}{lcr}
\hline Parameter $^{1}$ & Mean \pm SE & \multicolumn{1}{c}{$95 \%$ CI } \\
\hline$g 0$ & $0.043 \pm 0.013$ & $0.024-0.078$ \\
$\sigma(\mathrm{m})$ & $1963 \pm 279$ & $1464-2562$ \\
Leopards $/ 100 \mathrm{~km}^{2}$ & $2.599 \pm 0.957$ & $1.292-5.231$ \\
\hline
\end{tabular}

${ }^{1} g o$, probability of capture at the home range centre; $\sigma$, spatial parameter related to home range size.

National Park came from highly productive riverine forests (Bailey, 1993) and savannah woodlands (Maputla et al., 2013), Xonghile Game Reserve predominantly comprises nutrient-poor, lower-productivity sandveld, which sustains lower animal densities (Redfern et al., 2003; Scholes et al., 2003). The relatively high level of protection in the Reserve (LA \& KTE, unpubl. data) suggests that the low prey densities are not a result of human hunting activities.

Nonetheless, the Reserve could be acting as a population sink for leopards dispersing from Kruger National Park, through anthropogenic mortalities occurring in the adjacent non-protected areas. Estimates for anthropogenic leopard mortalities in the area are not available, but it is possible that individuals venturing into the non-protected areas adjoining the Reserve could be suffering relatively high anthropogenic mortality rates, which could lower population densities and attract leopards from surrounding areas (e.g. Kruger National Park). This vacuum effect has been documented for large carnivores and leopards in particular, and it may cause edge effects that affect the interior of even large protected areas (Loveridge et al., 2007). Longer term camera trapping or tracking using collars equipped with global positioning system units, combined with social surveys targeting the communities outside the Reserve, are necessary to ascertain whether this affects leopards in and around Xonghile Game Reserve.

\section{Methodological considerations and sex-specific parameters}

The majority of our stations had only one camera trap, rather than the recommended two-camera set-up (one for 
each flank; Karanth, 1995), allowing us to survey a larger area and thus increase the number of captured individuals, with limited resources. Although we believe that this was the best approach in our case, the trade-offs between surveying a larger area and obtaining higher identification rates should be considered on a case-by-case basis.

Although males commonly occupy territories overlapping with those of 2-4 females (Bailey, 1993), more males $(n=5)$ than females $(n=2)$ were captured during our study (the sex of two individuals could not be determined). Maputla et al. (2013) also recorded a male-bias in capture rates and cited several potential reasons for this, including heterogeneity in behaviour between sexes in the vicinity of the trap, and in tendencies to use specific trap locations, such as roads (Krebs, 1999).

The model with the highest support was that in which sex did not influence the detection $(g o)$ or scale $(\sigma)$ parameters. However, rather than indicating the absence of widely described sex-dependent heterogeneity in behaviour and ranging patterns (Bailey, 1993; Kittle et al., 2017), we believe that the relatively small sample size did not provide enough data to facilitate the inference and modelling of sex-specific differences in detectability and ranging patterns.

\section{Implications for conservation policy in Mozambique}

Trophy hunting has the potential to benefit the conservation of large carnivores (Lindsey et al., 2007; Loveridge et al., 2007), and it is estimated that each leopard hunted in Mozambique could contribute c. USD 24,00o to the local and national economy (Jorge et al., 2013). However, if hunting is poorly managed or adds to other sources of anthropogenic mortality, it can reduce numbers to such an extent that a population is no longer viable in the long term. Demonstrating that hunting practices, including quotas, are biologically sustainable is therefore essential for trophy hunting to be an effective tool in the management and conservation of large African carnivores (Swanepoel et al., 2014; Braczkowski et al., 2015).

Our results lead us to question the reliability of the estimates employed to set quotas for hunting leopards in Mozambique. The study by Martin \& de Meulenaer (1988), quoted as the primary justification for a recent increase of the trophy export quota in Mozambique (from 60 to 120 individuals per annum; CITES, 2007), states that up to $80 \%$ of the country supports leopard densities of $3^{-10}$ individuals $/ 100 \mathrm{~km}^{2}$. It also suggests that only $3 \%$ of the country's total land area should have leopard population densities lower than that found in our study. However, our estimate of 2.60 leopards/100 $\mathrm{km}^{2}$ in Xonghile Game Reserve, one of the better protected areas in the country, suggests that it is unlikely that many areas in Mozambique support the densities cited in the application for a revision of the hunting quota. Although some landscapes will have higher primary productivity levels than the Reserve, it is likely that high levels of anthropogenic disturbances in large parts of the country (Hatton et al., 2001) would more than counteract this. Thus, although we appreciate that trophy hunting has not taken place in the Reserve for nearly 10 years (LA \& KTE, unpubl. data) and we acknowledge the limitations of our study in terms of the number of individuals encountered relative to the overall range and total size of the population, we believe it is unlikely that leopard densities as high as those cited in the application for a quota increase are common in areas where hunting currently takes place.

We therefore recommend further assessments of leopard population status and densities across different habitats and land-use types across the country, in both hunting and protected areas. This would be an important step towards the development of a sustainable and empirical quota allocation system, similar to that currently being developed for South Africa, which includes hunting regulations based on leopards' age, adaptive management strategies, and dynamic, evidence-based quota systems (Department of Environmental Affairs, 2017). Camera trapping surveys are a rapid method for obtaining robust estimates of leopard numbers at a moderate cost (Balme et al., 2009) and, if followed by effective management interventions, could play an important role in the species' recovery and conservation in many post-conflict landscapes across the country.

The conservation challenges we have identified are not exclusive to Mozambique, with Tanzania and Namibia also employing the density estimates of Martin \& de Meulenaer (1988) for justifying modifications, approved by CITES (CITES, 2002, 2004), of quotas for hunting leopards. Our results reinforce the need for caution when setting hunting quotas for leopards, and the importance of reliable population estimates across the species' range. We recommend similar research be carried out in other regions where such estimates are used to set harvest quotas, to support a shift towards evidence-based guidance of management and policy.

Acknowledgements We thank the Director of National Conservation Areas Mozambique for granting $\mathrm{KE}$ and LA research permits (005-2011/003-2012), the shareholders of Xonghile Game Reserve for allowing access, the Centre for Wildlife Management, University of Pretoria, and Wilderness Trust for financial support, and Valeria Boron and Charlotte E. Searle for their help with the analyses.

Author contributions Data collection: LA and KE; analyses: PS; writing: all authors.

\section{Conflicts of interest None.}

Ethical standards All research carried out complied with the Oryx Code of Conduct. 


\section{References}

Alexander, J.S., Gopalaswamy, A.M., Shi, K. \& Riordan, P. (2015) Face value: towards robust estimates of snow leopard densities. PLoS ONE, 10, e0134815.

B AILEy, T.N. (1993) The African Leopard: Ecology and Behavior of a Solitary Felid. Columbia University Press, New York, USA.

Balme, G., Hunter, L.T.B. \& Slotow, R. (2009) Evaluating methods for counting cryptic carnivores. Journal of Wildlife Management, 73, 433-441.

Balme, G., Slotow, R. \& Hunter, L.T.B. (2010) Edge effects and the impact of non-protected areas in carnivore conservation: leopards in the Phinda-Mkhuze Complex, South Africa. Animal Conservation, 13, 315-323.

Balme, G.A., Lindsey, P.A., Swanepoel, L.H. \& Hunter, L.T.B. (2014) Failure of research to address the rangewide conservation needs of large carnivores: leopards in South Africa as a case study. Conservation Letters 7, 3-11.

Borah, J., Sharma, T., Das, D., Rabha, N., Kakati, N., Basumatary, A. et al. (2013) Abundance and density estimates for common leopard Panthera pardus and clouded leopard Neofelis nebulosa in Manas National Park, Assam, India. Oryx, 48, 149-155.

Borchers, D. \& EFFord, M. (2008) Spatially explicit maximum likelihood methods for capture-recapture studies. Biometrics, 64, 377-385.

Boron, V., Tzanopoulos, J., Gallo, J., Barragan, J., Jaimes-Rodriguez, L., Schaller, G. \& Payán, E. (2016) Jaguar densities across human-dominated landscapes in Colombia: the contribution of unprotected areas to long term conservation. PLoS ONE, 11(5), e0153973.

Bothma, J. Du P. \& Le Riche, E.A. (1984) Aspects of the ecology and the behaviour of the leopard Panthera pardus in the Kalahari desert. Koedoe, 27, 259-279.

Braczkowski, A.R., Balme, G.A., Dickman, A., Macdonald, D. W., Fattebert, J., Dickerson, T. et al. (2015) Who bites the bullet first? The susceptibility of leopards Panthera pardus to trophy hunting. PLoS ONE, 10(4), eo12310o.

Burnham, K.P. \& Anderson, D.R. (2002) Model Selection and Multimodel Inference: A Practical Information-Theoretic Approach Springer, New York, USA.

Chase Grey, J.N., Kent, V.T. \& Hill, R.A. (2013) Evidence of a high density population of harvested leopards in a montane environment. PLoS ONE, 8(12), e82832.

CITES (2002) Leopard: Amendment to the Quota of the United Republic of Tanzania. Document CoP12 Doc. 23.1.2. CITES, Geneva, Switzerland.

CITES (2004) Leopard: Export Quota for Namibia. Document CoP13 Doc. 19.1. CITES, Geneva, Switzerland.

CITES (2007) Leopard Export Quotas for Mozambique. Unpublished report. Fourteenth meeting of the Conference of the Parties, The Hague, Netherlands.

Department of Environmental Affairs of the Republic of South Africa (2017) Department of Environmental Affairs confirms extension of zero quota for leopard hunting in South Africa. Https:// www.environment.gov.za/mediarelease/deaconfirmsextension_ zeroquotaofleopardhunting [accessed 8 January 2018].

Efford, M.G. (2004) Density estimation in live-trapping studies. Oikos, 106, 598-610.

Efford, M.G. (2015) Spatially explicit capture-recapture models. $R$ package version 2.9.5. Https://cran.r-project.org/package $=$ secr [accessed 1 May 2017].

Goldberg, J.F., Tempa, T., Norbu, N., Hebblewhite, M., Mills, L. S., WANGCHUK, T.R. \& LuKaCs, P. (2015) Examining temporal sample scale and model choice with spatial capture-recapture models in the common leopard Panthera pardus. PLoS ONE, 10(11), e0140757.

Gray, T.N.E. \& Prum, S. (2012) Leopard density in post-conflict landscape, Cambodia: evidence from spatially explicit capture-recapture. Journal of Wildlife Management, 76, 163-169.

HANKs, J. (2000) Southern Africa in the conservation of mammalian biodiversity. In Priorities for the Conservation of Mammalian Diversity: Has the Panda had its day? (eds A. Entwistle \& N. Dunstone), p. 239. Cambridge University Press, Cambridge, UK. Hatton, J., Couto, M. \& Oglethorpe, J. (2001) Biodiversity and War: A Case Study of Mozambique. Unpublished report. Biodiversity Support Program, Washington, DC, USA

Henschel, P., Hunter, L.T.B., Coad, L., Abernethy, K.A. \& Muhlenberg, M. (2011) Leopard prey choice in the Congo Basin rainforest suggests exploitative competition with human bushmeat hunters. Journal of Zoology, 285, 11-20.

Jackson, P. (1989) A Review by Leopard Specialists of the Status of Leopard in sub-Saharan Africa by Martin and de Meulenaer. Submitted to the seventh meeting of the CoP to CITES, Lausanne, Switzerland.

Jacobson, A.P., Gerngross, P., Lemeris, JR, J.R., Schoonover, R.F., Anco, C., Breitenmoser-Würsten, C. et al. (2016) Leopard (Panthera pardus) status, distribution, and the research efforts across its range. PeerJ, 4, e1974.

Jorge, A.A., Vanak, A.T., Thaker, M., Begg, C. \& Slotow, R. (2013) Costs and benefits of the presence of leopards to the sporthunting industry and local communities in Niassa National Reserve, Mozambique. Conservation Biology, 27, 832-843.

Karanth, K.U. (1995) Estimating tiger Panthera tigris populations from camera-trap data using capture-recapture models. Biological Conservation, 71, 333-338.

Kittle, A.M., Watson, A.C. \& Fernando, T.S.P. (2017) The ecology and behaviour of a protected area Sri Lankan leopard (Panthera pardus kotiya) population. Tropical Ecology, 58, 71-86.

Krebs, C.J. (1999) Ecological Methodology. 2nd edition. Addison Wesley Longman, Boston, USA.

Lindsey, P.A., Roulet, P.A. \& Romanach, S.S. (2007) Economic and conservation significance of the trophy hunting industry in sub-Saharan Africa. Biological Conservation, 134, 455-469.

Loveridge, A.J., Searle, A.W., Murindagomo, G. \& Macdonald, D.W. (2007) The impact of sport-hunting on the population dynamics of an African lion population in a protected area. Biological Conservation, 134, 548-558.

Maputla, N.W., Chimimba, C.T. \& Ferreira, S.M. (2013) Calibrating a camera trap-biased mark-recture sampling design to survey the leopard population in the N'wanetsi concession, Kruger National Park, South Africa. African Journal of Ecology, 51, 422-430.

Martin, R.B. \& De Meulenaer, T. (1988) Survey of the status of the leopard (Panthera pardus) in Sub-Saharan Africa. Report submitted to the Secretariat of the Convention on International Trade in Endangered Species of Wild Fauna and Flora, Lausanne, Switzerland.

Martins, Q. \& Harris, S. (2013) Movement, activity and hunting behaviour of leopards in the Cederberg mountains, South Africa. African Journal of Ecology, 51, 571-579.

Noss, A., Polisar, J., Maffei, L., García, R. \& Silver, S. (2013) Evaluating Jaguar Densities with Camera Traps. WCS, New York, USA.

Nowell, K. \& Jackson, P. (1996) Wild Cats: Status Survey and Conservation Action Plan. Burlington Press, Cambridge, UK.

R Development Core Team (2015) R: A Language and Environment for Statistical Computing. Http://www.r-project.org [accessed 8 June 2018]. 
Redfern, J.V., Grant, R., Biggs, H. \& Getz, W.M. (2003) Surface-water constraints on herbivore foraging in the Kruger National Park, South Africa. Ecology, 84, 2092-2107.

Royle, J.A., Nichols, J.D. \& Karanth, K.U. (2009) A hierarchical model for estimating density in camera-trap studies. Journal of Applied Ecology, 46, 118-127.

Scholes, R.J., Bond, W.J. \& Eckhardt, H.C. (2003) Vegetation Dynamics in the Kruger Ecosystem. The Kruger Experience. Island Press, Washington, DC, USA.

Sollmann, R., Furtado, M., Gardner, B., Hofer, H., Jacomo, A., Torres, N. \& Silveira, L. (2011) Improving density estimates for elusive carnivores: accounting for sex-specific detection and movements using spatial capture-recapture models for jaguars in central Brazil. Biological Conservation, 144, 1017-1024.

Stander, P.E., Haden, P.J. \& Kaqece, G. (1997) The ecology of asociality in Namibian leopards. Journal of Zoology, 242, 343-364.
Stein, A., Andreas, A. \& Aschernborn, O. (2011) Namibian National Leopard Survey 2011, Final Report. Unpublished report. Namibian Ministry of Environment and Tourism, Windhoek, Namibia.

Swanepoel, L., Lindsey, P., Somers, M.J., Van Hoven, W. \& Dalerum, F. (2014) The relative importance of trophy harvest and retaliatory killing of large carnivores: South African leopards as a case study. South African Journal of Wildlife Research, 44, $115-134$.

Swanepoel, L., Somers, M. \& Dalerm, F. (2015) Density of leopards Panthera pardus on protected and non-protected land in the Waterberg Biosphere, South Africa. Wildlife Biology, 21, 263-268.

Tobler, M.W. \& Powell, G.V.N. (2013) Estimating jaguar densities with camera traps: problems with current designs and recommendations for future studies. Biological Conservation, 159, 109-118. 